\title{
Development of flood mapping techniques and their efforts on flood assessment and management in European coastal cities
}

\author{
Maria Fabrizia Clemente ${ }^{1, a}$ and Zhuyu Yang ${ }^{2}$, Bruno Barroca ${ }^{2}$ \\ ${ }^{1}$ University of Naples Federico II, Department of Architecture, Napoli, Italy \\ ${ }^{2}$ Lab'urba, Université Gustave Eiffel, Marne-la-Vallée, France
}

\begin{abstract}
Coastal areas are highly vulnerable to climate change and, in these areas as elsewhere, the assessment and management of climate risks is a key issue. Among natural hazards, flood is one of the most damaging. Flood mapping supports risk assessment and management. In the last decade, new technologies have allowed many innovations in cartography, both in the data acquisition, processing, and modelling phases. In flood mapping, the identification of data and the methodological approach are the first key aspects. Other fundamental aspects are the visualization, transfer and communication of data to different users. Graphic semiology is the discipline that identifies the techniques that make data usable. In this contribution, key steps of flood mapping are analysed, through the study of techniques and products. Furthermore, possible directions for mapping research and development to support flood assessment and management are identified. To validate the theories, the process of developing a flood risk map of road system will be illustrated.
\end{abstract}

\section{Introduction}

Coastal zones are areas of transition and high interaction between the terrestrial and the marine environment, vital areas for the biosphere where continuous exchanges of energy and matter take place in a mutual and continuous equilibrium. The natural richness of the coastal zone has allowed the development of many activities and the establishment of numerous cities. However, at the same time the areas are highly vulnerable from both environmental and climatic aspects (Crossland et al., 2016).

Compared to the pre-industrial period, by the end of the 21 st century, global temperatures are expected to increase from $+1.5^{\circ}$ to $+2^{\circ}$. The change of temperature directly rise the frequency and intensity of natural phenomena, such as sea level rise, sea temperature and concentration of $\mathrm{CO}_{2}$ and consequently acidification of water, intensification of extreme weather events (cyclones, storms and storm surges), alteration of wave motion, alteration of precipitation, and finally the increase of run-off (Nicholls et al., 2007).

In major coastal cities, flood risk is a critical hazard in terms of damage to people and to the built and natural environment (Hallegatte et al., 2013). Flood is defined as the overflowing of the normal confines of a water body or the accumulation of water in areas normally without it. Floods can occur due to a variety of causes such as river floods, flash floods, heavy rainfall, storm surges in coastal areas or failure of the sewerage system in urban areas (IPCC, 2018). In coastal areas, hazards are interconnected, e.g. gradual sea level rise contributes to erosion phenomena accelerating the dynamics of sediment transport. At the same time, erosion and sea level rise increase the likelihood and intensity of possible flooding due to tides, storm surges, wind or heavy rainfall (Zhu et al., 2010).

In recent decades, with the introduction of computer modelling and mapping, coastal flood risk analysis has been greatly improved. Flood mapping is a crucial component of flood risk management process, in which advances in analytical modelling must be accompanied by advances in communication and dissemination of information (Coller et al., 2018).

There are many research institutions working on risk assessment through multiple projects such as EUROFlood, EUROTAS, FLOODAWARE, FLOODsite, FLOOD-serv, FLOODS or LISCOAST. Several large-scale European flood maps have been developed. Despite the significant socio-economic impacts of coastal flooding and the imperative menaces of climate change, there is a lack of information and predictive capability of local-scale modelling, mainly due to the complexity of coastal environment and the strong interaction between different hazards (Paprotny et al., 2019).

In the context of flood risk management planning in Europe, a positive impulse was given with the introduction of the 2007 European Flood Directive focusing on flood risk assessment and management. In addition, two specific directives for coastal zone management can be highlighted: the Maritime Spatial Planning (MSP) and the Integrated Coastal Zone Management (ICZM)

${ }^{a}$ Corresponding author: mariafabrizia.clemente@unina.it

DOI 10.3311/FLOODRisk2020.9.32 
(2013/0074/COD). The two instruments are complementary: the MSP plans define a mapping of existing human activities and identify possible future developments, while the ICZM aims to ensure an integrated management of these activities (Addis et al., 2015). The MSP is one of the main instruments for the implementation of the ICZM in the marine part of the coastal zone, and the integrated application of the two instruments is necessary due to the strong environmental, social and economic interactions between land and sea (Ramieri, Bocci et Markovic, 2019). Both directives must be applied in coherence with the Water Framework Directive (WFD) (2000/60/EC).

The article aims to identify the key steps of traditional coastal and non-coastal flood mapping methodologies and contextualise them in the contemporary era, characterized by the big data and the new technologies. Finally, will be identify future research and development prospects for coastal flood mapping.

\section{Flood hazard and flood risk mapping}

Flood mapping allows the visualisation of the results of floods assessments, and the two processes are therefore closely interrelated. Four phases can be identified: assessment, evaluation, management and measuring (IRGC, 2006). The mapping phases mainly support the assessment and management phases where the visualisation of flood hazard, flood risk and of management options, in the geographical context, is very important.

Assessment and mapping processes are complex, multidisciplinary and involve technical, social ecological and economic aspects, requiring specific, systemic, and rigorous methodological approaches. To prepare a flood map, it is essential to define the purpose, the target audience, the covered area and therefore the degree of detail and the scale (APFM, 2013).

In the article 6 of the European Flood Risk Directive, the European Union requires its member states to prepare flood hazard maps and flood risk maps. Flood hazard represents the potential occurrence of a natural or human induced event, trend or physical impact that may cause loss of life or damage to health, as well as damage to buildings, infrastructure, services, ecosystems and/or resources (IPCC, 2014). Flood risk is the combination of the probability of a flood event and of the potential negative consequences associated, so flood risk maps show the consequences associated with the flood scenarios presented in the flood hazard maps. The hazard map is therefore the fundamental input for the vulnerability and risk maps and can be obtained through an historical, geomorphological, or modelling approach.

Flood mapping supports spatial planning, prevention, through preliminary assessment and risk management planning, response and recovery phases after critical events. It also supports the increase of risk awareness among the public and insurance management (van Alphen et al, 2009). The types and main characteristics of flood hazard maps (Tab. 1) and flood risk maps (Tab. 2) are illustrated. Other types of maps such as emergency maps or insurance maps complete flood risk assessment (Excimap, 2007).

\begin{tabular}{|c|c|}
\hline Maps & Main characteristics \\
\hline $\begin{array}{c}\text { Flood hazard } \\
\text { maps }\end{array}$ & Spatial distribution of flood hazard \\
\hline Flood extent map & $\begin{array}{c}\text { Spatial distribution of possible floods } \\
\text { for given probabilities }\end{array}$ \\
\hline Flood depth map & $\begin{array}{c}\text { Spatial distribution of water height } \\
\text { obtained through 2D and 1D models }\end{array}$ \\
\hline $\begin{array}{c}\text { Flow velocity and } \\
\text { flood propagation } \\
\text { map }\end{array}$ & $\begin{array}{c}\text { Spatial distribution of flood hazard } \\
\text { through water flow velocity and/or } \\
\text { velocity of flood propagation }\end{array}$ \\
\hline $\begin{array}{c}\text { Flood danger map } \\
\text { Spatial distribution of the degree of } \\
\text { flood hazard (in terms of depth, } \\
\text { velocity, debris, frequency), the } \\
\text { evaluation can be quantitative or } \\
\text { qualitative }\end{array}$ \\
\hline Event map & $\begin{array}{c}\text { Spatial distribution of the historical } \\
\text { events }\end{array}$ \\
\hline
\end{tabular}

Table 1. Types and contents of flood hazard maps, own elaboration from (Excimap, 2007).

\begin{tabular}{|c|c|}
\hline Maps & Main characteristics \\
\hline $\begin{array}{c}\text { Vulnerability } \\
\text { maps }\end{array}$ & $\begin{array}{c}\text { Spatial distribution of vulnerabilities } \\
\text { such as population, assets, } \\
\text { infrastructures, and activities } \\
\text { potentially affected by a flood }\end{array}$ \\
\hline $\begin{array}{c}\text { Flood defences } \\
\text { map }\end{array}$ & $\begin{array}{c}\text { Spatial distribution of defence } \\
\text { systems and/or their ability to protect } \\
\text { natural and/or anthropic systems }\end{array}$ \\
\hline $\begin{array}{c}\text { Flood damage } \\
\text { map }\end{array}$ & $\begin{array}{c}\text { Spatial distribution of potential } \\
\text { damage elements, existing or related } \\
\text { issues in flood hazard areas, such as: } \\
\text { population, infrastructures, activities, } \\
\text { heritage, buildings, etc. }\end{array}$ \\
\hline
\end{tabular}

Table 2. Types and contents of flood risk maps, own elaboration from (Excimap, 2007).

The challenges in mapping urban coastal flooding derive from complexity the phenomena and of the coastal environment. Coastal flooding is in fact the product of several hazards, event-based, such as storm surge and wave action, or gradual, such as high tide and sea level rise. At the same time, defence systems greatly influence the mapping, making necessary more accurate modelling.

\section{Cartography and cybercartography for flood risk mapping}

Cartography, the discipline that focuses on the study of maps, was born in ancient times as a tool to support humans in their travels and explorations. The aim of cartographers has always been to find the right balance between the multiple information that maps contain and communicate and the most realistic reproduction of territories. The introduction of new technologies has changed the ways in which maps work through representation, visualisation, and design (MacEachren, 1995). 
Coastal flood mapping has been developed in recent years and the wide variety of models has replaced the traditional use of paper maps thanks to the use and facilities of web mapping (Batista, 2018). To produce risk maps, paper o digital, it is necessary to:

1) identify data sources and methodological approach;

2) transform data into usable information through graphic semiology;

3) merge all the information operating an overlay;

4) and finally, analyse the data.

The four steps are represented and described in the following paragraphs, through the exemplification process of the elaboration of flood damage map of roads-buildings system in a coastal area.

Road transport system is one of the critical infrastructures most impacted by flood events and, at the same time, has a fundamental role allowing the movement of people and assets especially during emergencies events (Pregnolato et al., 2017).

\subsection{Data identification and methodological approach}

In the processes of climate risk assessment and management, the knowledge of territories and hazards requires the integration of both technical and operational expertise. Cartographers identify the main data sources and methodological approach to develop flood maps as firsts key aspects in relation to the accuracy and to the degree of detail and to the scale.

Before the advent of new technologies, were used to construct maps written texts, such as newspaper articles or detailed reports, historical photographs, historical maps (Fig. 1) or even paintings and data, archived in libraries or in national archives. In recent times, a multitude of written and geographic data can be used, obtained through modelling and simulations, surveys, investigations, and remote sensing data processing (APFM, 2013).

For flood mapping, two essential data are hazard data (historical or obtained through simulation models) and an accurate topography of the terrain. In order to complete the analysis, data on land use and related information are required, including data on population, socio-economic aspects, presence of critical infrastructure, protected natural environments among others.

For example, for analysing the road system impacted by flood scenarios, are necessary at least two database, road infrastructures and flooded areas, showing the necessity of multiple data to understand direct and indirect impacts.

\subsection{Graphic Semiology}

To transform the main data sources into usable information, it is necessary to graphicise the data. In the flood risk assessment process, the main problem is how the information is communicated and perceived by stakeholders.

Data representation and visualization are one of the main issues in the production of flood maps. The discipline that deals with the representation of data and information is the graphic semiology. Jacques Bertin, in his book Sémiologie graphique, shows how the three elements of the plane (points, lines and polygons), adequately positioned, can be represented through six visual variables: size, value, grain, colour, orientation and shape (Bertin, 1967; Fig. 1).
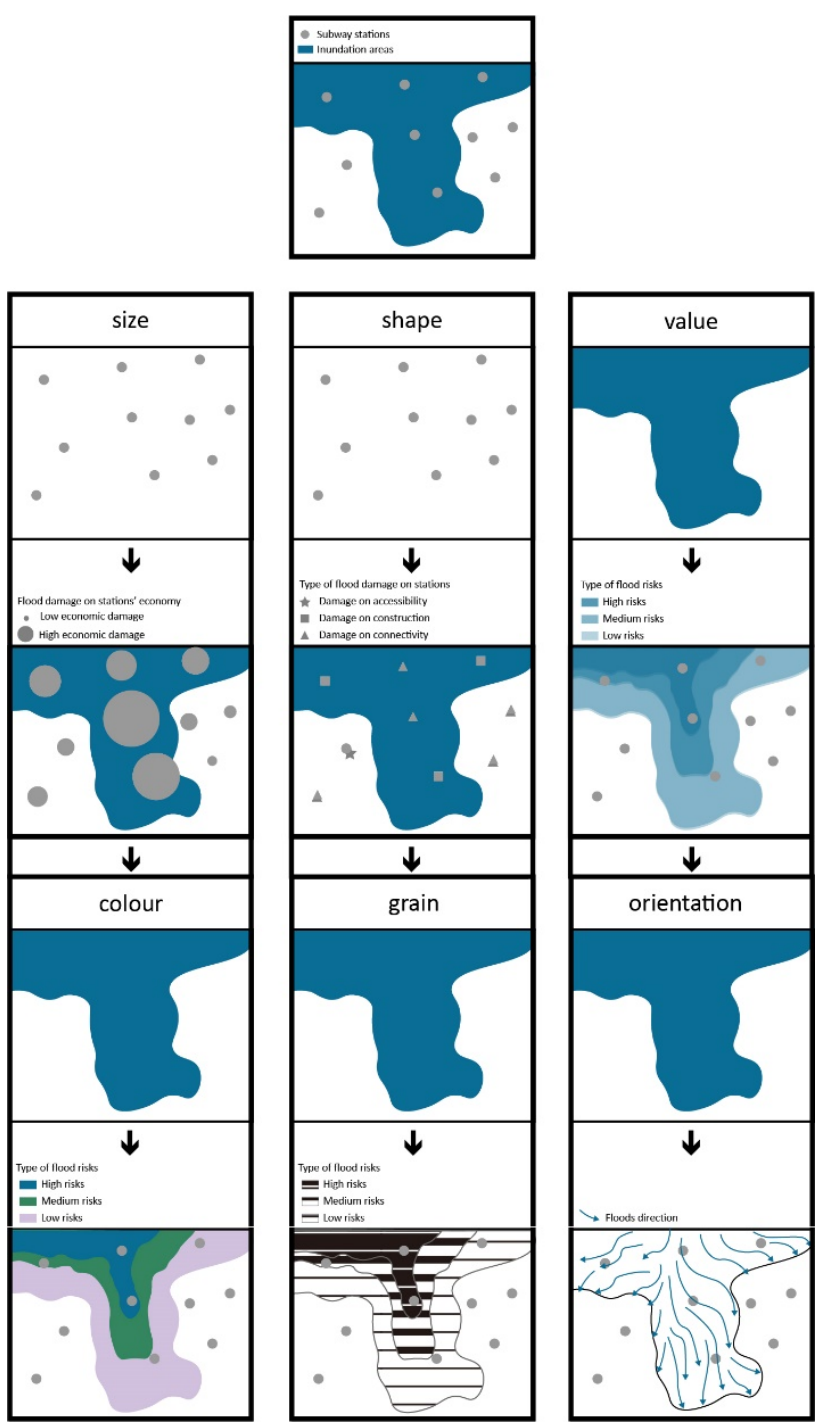

Figure 1. Application of the six visual variables of J. Bertin for flood mapping, exemplification of a flood map of subways stations. Edited by the authors.

The professor and geographer Gilles Palsky points out, in his research, how the principles introduced by Bertin can be considered as a new "grammar" based on the preliminary analysis of the information (the meaning) and the means of the graphic system (the signifier). This grammar is made up of rules, e.g. for the construction of images it is fundamental the correct use of visual variables and the rules of legibility considering the reading capacity of the human eye. Is, for example, important the selection of the correct density of symbols or the correct separation between figures. The application of the rules is a guarantee of effective communication (Palsky and Robic, 2000; Palsky, 2012).

An example of the application of graphic semiology is shown in (Fig. 2). 


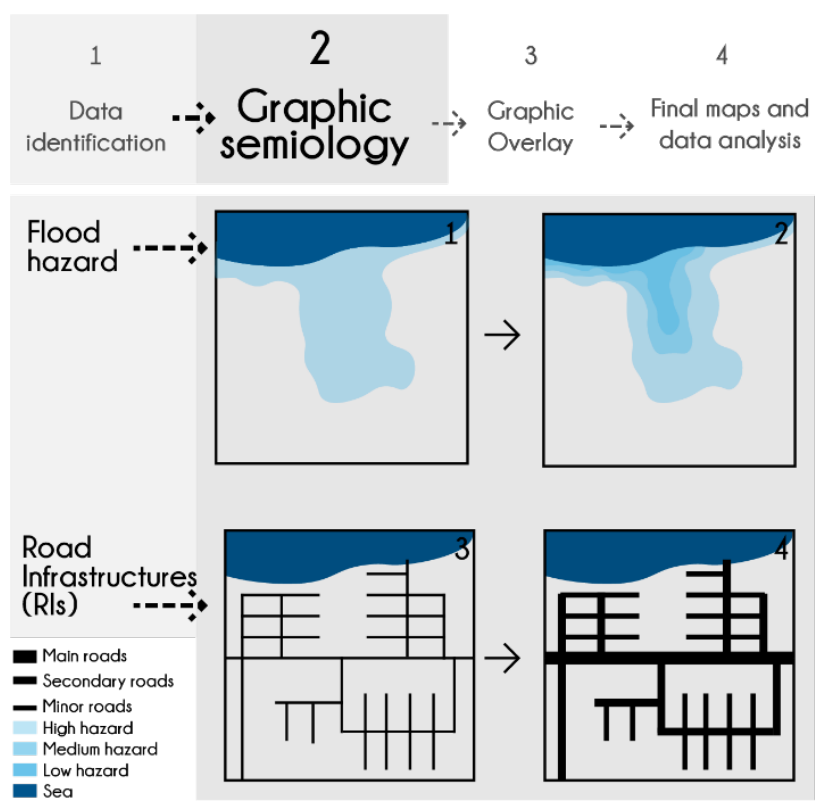

Figure 2. Graphic semiology, application on flood mapping for the road infrastructures system. Edited by the authors.

In figure 2 the road infrastructures system is represented by lines, the flooded areas by polygons (maps 1 and 3). Through the use of colour and size variables it is possible to identify the degree of risk determinates from the flood hazard level classified as high risk, medium risk and low risk (map 2). Furthermore, roads are classified in function of its importance as main road, secondary road and minor road (map 4).

\subsection{Graphic Overlay}

After data graphicisation, it is necessary to transform data into usable information.

The third step is the overlay method that has its roots in the famous book "Design with nature" by landscape architect Ian McHarg, known as the first intellectual who brought ecological planning to the attention of a mass audience (McHarg, 1969). McHarg's intuition was to superimpose transparent films containing different information on a base map creating a spatial model and recognising the analyses as an integral part of the design processes. Today, with the development of computer technology, it is possible to archive and visualise digital data in multiple layers using tools such as GIS or CAD systems (Herrington, 2010).

By overlaying different data or maps, containing information of different origins and nature, it is possible to create composite maps to understand the complex nature of the urban environment. The overlaying of the different layers allows to visualize multiple information simultaneously and its therefore a complex operation that requires appropriate graphic techniques. Aspects of risk perception and communication, in fact, are key issues in the flood management cycle, as they contribute to public awareness and thus can influence the collective behaviours (Kellens et al., 2013).

An example of the application of graphic overlay is shown in (Fig. 3).

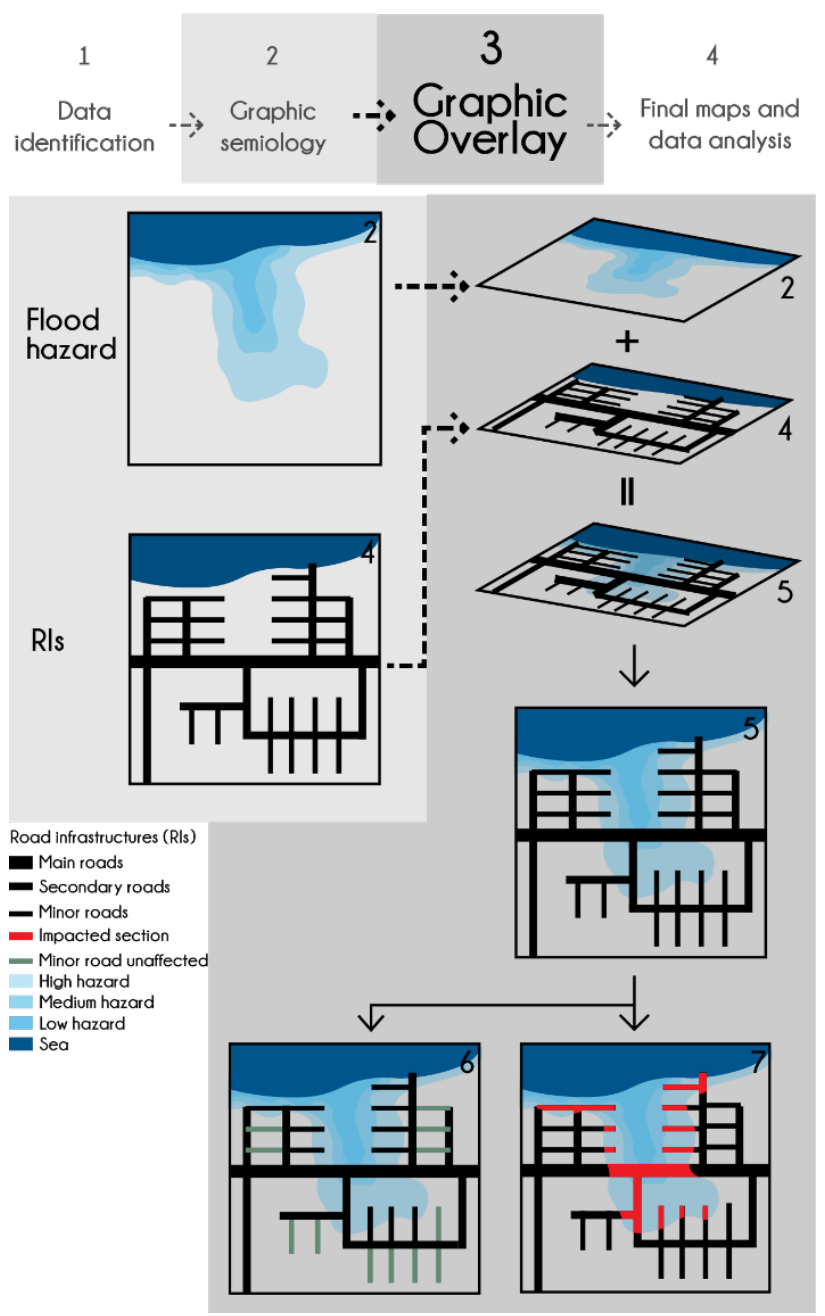

Figure 3. Graphic overlay, application on flood mapping for the road infrastructures system. Edited by the authors.

Figure 3 shows an overlay (map 5) of the flood hazard map (map 2) and of the road infrastructures map (map 4). The interpretation of the maps is always subjective, e.g. the user can see both the non-flooded roads (map 6) or the flooded ones (map 7). It is therefore important to understand what and how it should be communicated.

\subsection{Final maps and data analysis}

To create a flood risk map, the last step is the analysis of the data, which can be supported, or not, by others information.

Cartographers are the first to interpret the data and transform it into maps, then, the users have to interpret the graphical information (Sluter, 2001). Hazard and risk maps can greatly influence the awareness and risk perception of citizens, thus it is important to consider the target audience when developing maps (Houston et al., 2017).

An example of elaboration of the final damage maps for the road infrastructures impacted by coastal flooding is shown in (Fig. 4). Data analysis is entrusted to readers and so is always subjective. 

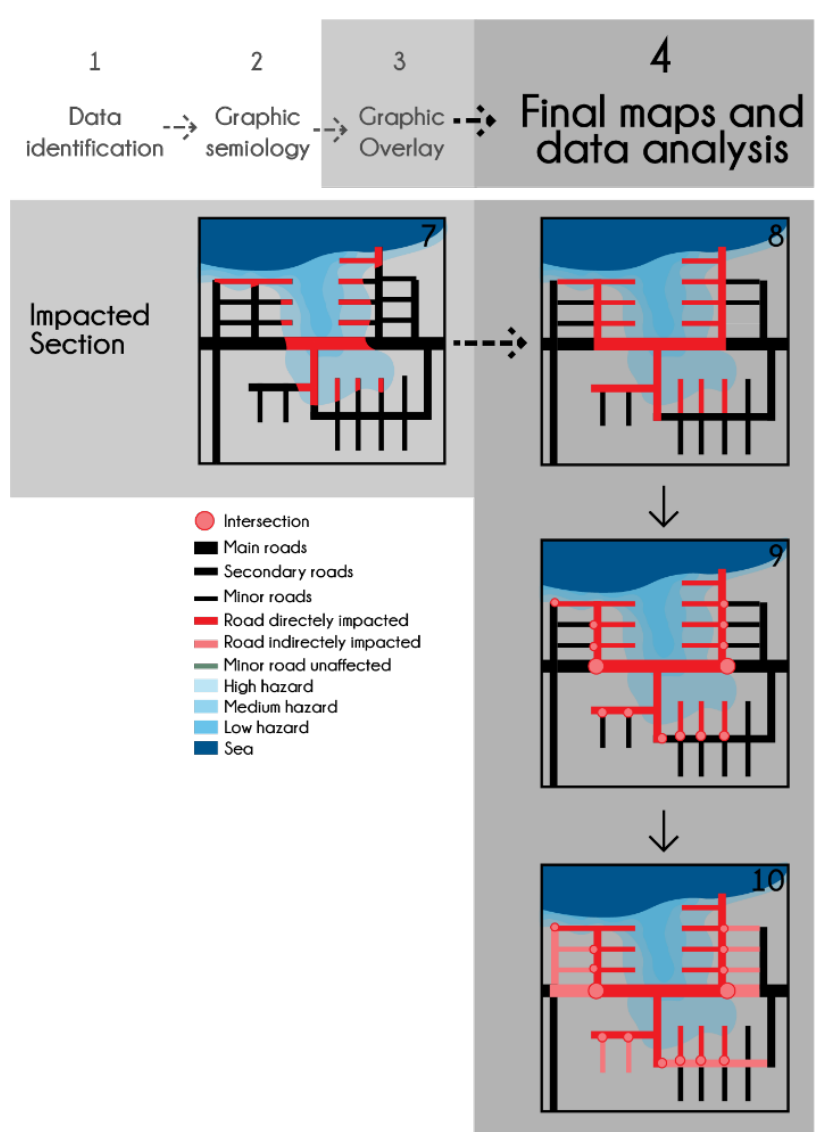

Figure 4. Final maps and data analysis, application on flood mapping for the road infrastructures system. Edited by the authors.

In the case of flooding on infrastructures, such as the road infrastructures, the interconnected nature of the system causes indirect damage over the spatial boundaries of the directly flooded area (Pant et al., 2018) as visible in Figure 4 (map 8). Considering intersections with other roads it is possible to identify as indirectly affected areas also crossroads (map 9) that could cause congestion also for roads not directly affected by floods (map 10).

From these initial analyses it is possible to carry out further analyses by replicating the processes. For example in Figure 5 is verify the accessibility of buildings that insist on the road infrastructures impacted by the flood event (Fig. 5).

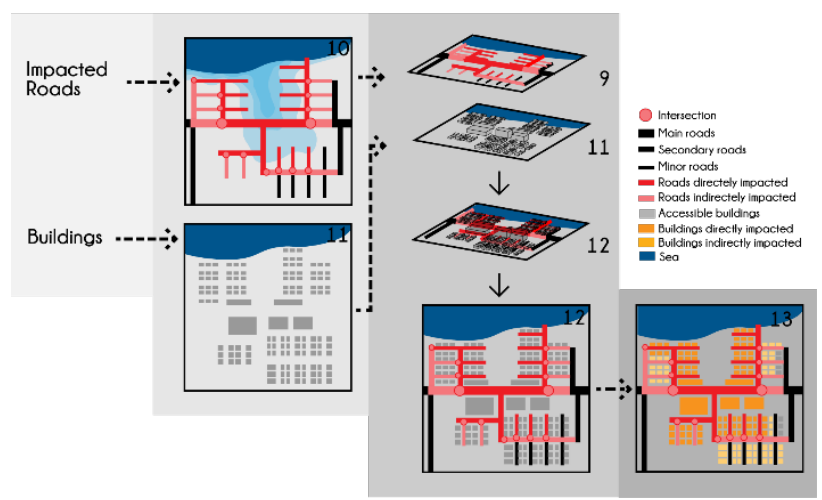

Figure 5. Final maps and data analysis, application on flood mapping for the road-building system. Edited by the authors.
As shown in Figure 5 there will be buildings whose access will be directly impacted (map 12) and some indirectly (map 13) (Fig. 5).

\subsection{Contribution of cybercartgraphy}

With the introduction of the Information and Communication Technologies (ICTs), such as Geographic Information System (GIS), web-based GIS platform and smartphone applications, maps have evolved into cybermaps and the way how data are visualized and used has changed. Key elements were the possibility to develop 3D maps, the association of attributes to cartographic elements, the georeferencing of data into maps and the user-defined parameterization. In recent times, the introduction of virtual reality and real time updates have made further improvements (Semmo et al., 2015).

The term "cybercartography" was introduced by Professor F. Taylor in his keynote speech during the 18th International Cartography Conference in Stockholm (Sweden), the term identifies the changing nature of maps and cartography related to the digital age (Taylor, 1997). Seven key concepts define the paradigms of cybercartography: maps are multimedia, multisensory and interactive instruments, including qualitative and quantitative information, are produced by interdisciplinary teams and can cover multiple topics responding to the demands of society creating research and development partnerships (Taylor, 2003).

Cybercartography contributes significantly to flood mapping by combining three functions: integration of multiple resources, simultaneous data visualisation and map overlay, allowing users to control settings and zooming in/out. There are several online platforms that use online GIS systems and that can be considered as open cybermaps such as the web Géoportail of the French government (https://www.geoportail.gouv.fr) or the US federal agency NOAA's service specifically for coastal areas (https://coast.noaa.gov/floodexposure/; Fig. 6).

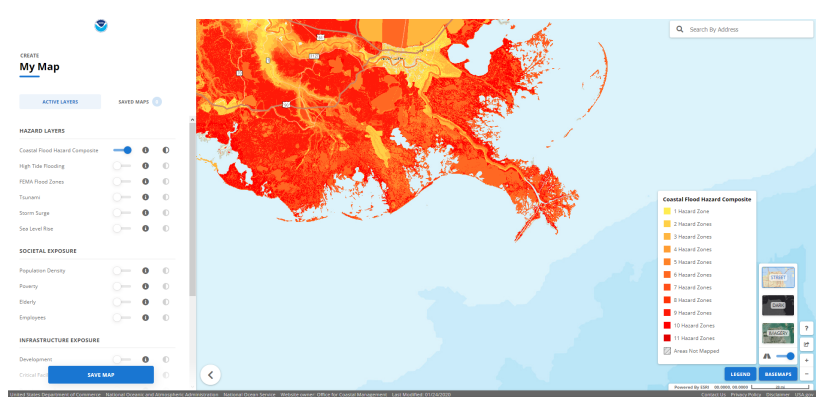

Figure 6. The Coastal Flood Exposure Mapper, a service powered by the US National Oceanic and Atmospheric Administration NOAA.

The synergy between GIS and cybercartography makes it possible to visualise and manage complex analyses of large volumes of geographical data. Tools from static have evolved into dynamic and geospatial big data have opened new fields of application in GIS systems (Ki, 2018).

Today, web-GIS platforms are an effective decision support tool for decision-makers and communication to citizens, interactivity and user parameterisation have 
become key requirements. Geovisualisations combine visualisation approaches from scientific computing, traditional cartography, image analysis, geographic information systems (GIS) for visual exploration, analysis, synthesis and presentation of georeferenced data (MacEachren et al., 2001).

\section{Current and future development}

The development of hazard and flood risk maps is a complex process of synthesis using different techniques. In coastal zones, the validation of flood risk maps is complex due to the highly dynamic characteristics of the phenomena, the exceptional nature of the events and the peculiarities of the coastal environment. Some parameters that can reduce the uncertainty of the maps are the quality and quantity of the data and the improvement of the flood simulation and visualisation processes.

\subsection{Quality of data sources}

The quality of the maps is closely related to the quality of the input data. The key data required to model coastal flooding are an accurate topographic model, tide levels, wave overtopping rates and floodplain friction parameters (Smith, 2012). The quality of information is a key issue especially in this historical era of abundance of information, in fact the data value derives from a rigorous approach to their use, in the aspects of selection, analysis and interpretation (Faghmous and Kumar, 2014).

Given the complexity of the urban coastal environment, among remote sensing data, satellite data are strategic assets for the continuous temporal update and for the global coverage, to analyse, monitor and manage both the variables linked to natural events and to the complexity that characterises the territories through a multiscalar, multitemporal and multisource approach. Through digital and smart processes, it is possible to extract data without needing an in-situ survey. Quantitative information about the built and natural environment are acquired through sensor registration and the data are produced as a multispectral raster image (Brivio et al., 2006).

For flood maps, detailed topography of terrain, DTM Digital Terrain Model (Fig. 7) or surface elevation, DEM - Digital Elevation Model, are crucial in terms of spatial resolution and accuracy (Van de Sande et al., 2012).

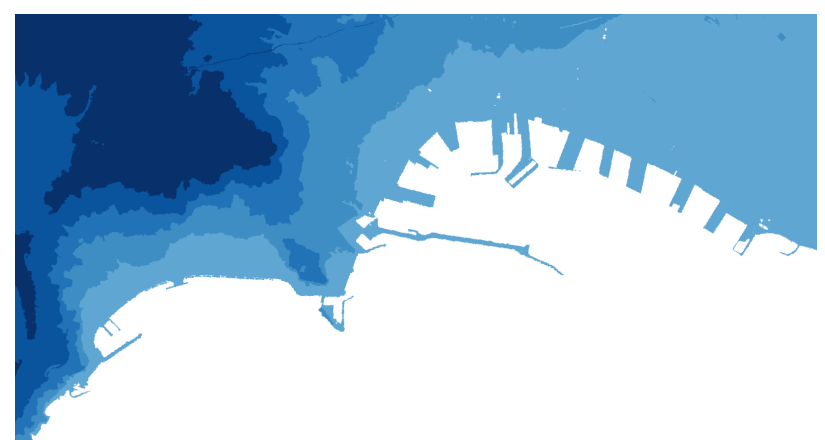

Figure 7. DTM - Digital Terrain Model Naples, obtained from the LIDAR relief of the National Remote Sensing Plan

MATTM 2007, elaboration on the Naples area. Edited by the authors.
Several open source databases are also available online, obtained by processing remote sensing images from planes, drones or satellites. Among them the MERIT DEM (Multi-Error-Removed Improved-Terrain DEM) developed by the University of Tokyo (Yamazaki et al. 2017). The resolution of the DEM model for reliable results is desirable to be less than $<10 \mathrm{~m}$ (Vousdoukaset al., 2012).

Also for climate data, there are a large number of datasets available online, as in the case of the JRC - Joint Research Centre Data Caralogue of the European Union, which has data from the Liscoast project - Large Scale Integrated Sea-level and Coastal Assessment Tool (https://data.jrc.ec.europa.eu/collection/liscoast).

While for hazard and topographic data, detailed information can be obtained thanks to the contribution of new technologies, socio-economic information still relates to large scales, requiring more analytical surveys to produce more detailed maps. Identification legends and, where necessary, accompanying texts should be included in the maps especially if the uncertainty that characterises events is to be communicated. In fact, representing even these parameters could lead to an overabundance of information making the map unclear, thus the use of appendices and accompanying texts is preferable (Bukvic et al., 2020).

\subsection{Quantity of data sources}

More data sources contribute to more accuracy in flood risk maps by creating multiple indicators to analyse specific vulnerabilities and exposed elements.

Geospatial big data have brought new challenges and opportunities for cartographic researchers in both technical, methodological and artistic aspects (Robinson et al., 2017). For example, through the use of socioeconomic, technological, ecological and organisational data sources, it is possible to investigate information on population structure, building characteristics or economic dynamics to develop urban resilience maps to flood risk (Serre and Heinzlef, 2018).

For land cover/land use, several open source databases are available online, obtained through remote sensing techniques. In this context, data from the European Copernicus Land Monitoring Service provide a mapping of the European coastline for a $10 \mathrm{~km}$ band identifying 71 land use classes through the Coastal Zones database. A more specific and detailed database, for the urban system, is the Urban Atlas, which consider 27 land use classes and it is available for the major coastal cities.

From the Urban Atlas, for example, it is possible to extract data about the road system with a discrete degree of detail. The spatial resolution is $10 \mathrm{~m}$. Applying a graphic overlay between the road system and the Digital Terrain Model (Fig.7) in the Naples area, it is possible to identify the roads that could be impacted by a flood event and thus define their vulnerability (Fig. 8).

Finally, concern the flood risk on road transport system, the possibility of acquiring big data in real time through social media alerts during a risk event allows authorities to intervene quickly in the areas that are most 
at risk through the use of GIS and GPS systems; however, this information must be appropriately selected (Smith et al., 2017).

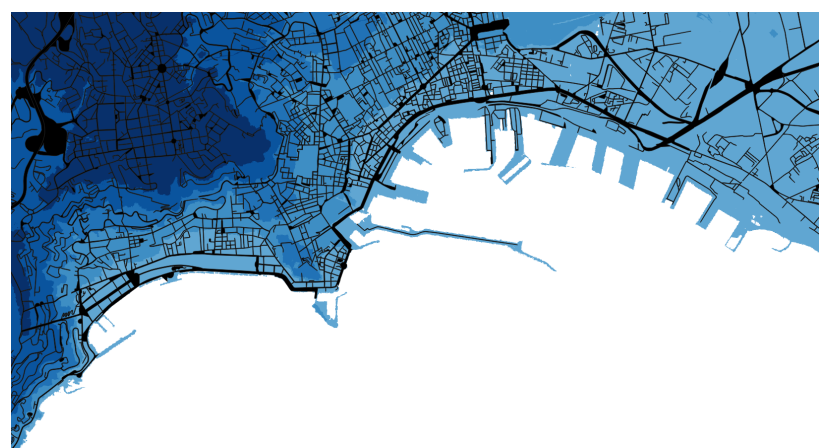

Figure 8. Overlay of the DTM obtained from the LIDAR relief of the National Remote Sensing Plan 2007 on the Naples area and the road system obtained from the Urban Atlas database of the Copernicus Land Monitoring service. Edited by the authors.

\subsection{D flood simulation and visualization}

Over the last decades, the technical and financial obstacles for flood simulations have become increasingly low, thanks to the increase in IT technology and accuracy, and to the growing availability of remote sensing data.

For hazard modelling there are two approaches the first and widely used considers inundated all areas below a certain depth of water and can be easily performed in a GIS system, but today new technologies allow more accurate modelling of coastal flooding processes through simulations that show overestimates of static models. However, the potential of GIS systems remains in the capability to analyse and assess vulnerable elements (Seenath et al., 2016). New technologies manage to integrate into the modelling the maximum height of the water comprising together with the SLR (Vousdoukas et al., 2016), as well as the effects of coastal defence and drainage (Gallien et al., 2014). From the modelling, datasets are then processed and made available online, often open source.

Traditional cartographic methods of visualisation and communication of flood analyses sometimes appear obsolete due to the impossibility of managing and representing both the complexity that characterises the territories of contemporary cities and the high dynamism that characterises natural hazards, in terms of intensity, frequency and scale (Barroca and Serre, 2018).

The origins and development of graphical semiology were founded on the visualisation of data on a twodimensional plane. Today, the conversion of maps into three-dimensional plans allows users to visualise both the simulation of water flows and the topographical complexity that characterises the territories (Jacquinod and Langumier, 2010). Three-dimensional visualisations bring numerous benefits by supporting plans, policies and projects in coherence with flood risk simulations and predictions by combining multiple data (Wang et al., 2019).
Video representations are also an effective communication tool to involve even less experienced users through gamification methods (Cornel et al, 2020).

\section{Conclusion}

Flood mapping is a key aspect of the hazard assessment and management process. Paper or digital maps must be produced with appropriately derived and classified data through rigorous methodological approaches.

For flood mapping, research is now pushing towards the integration of more and more accurate quantitative and qualitative data into specific support tools systems, such as GIS where empirical flood analyses can be carried out and mapped through overlay operations.

Thanks to the support of new technologies and the introduction of geospatial big data, new aspects of flood risk in urban areas can be investigated. In this context, the remote sensing sector is a strategic asset. Numerous open source databases are available online, such as the data offered by the European service Copernicus. In the big data era, the analysis of the state of the art shows the need of more detailed data on socio-economic aspects, while new computational support tools make possible accurate climate hazard simulations. Hazard information can be either calculated or obtained from multiple online databases.

The highly dynamic characteristics of the coastal environment and of the climate hazards suggest making maps in relation to the target audience, trough the graphic semiology. Graphic semiology, introduced by J. Bertin in the 1960s and today made a computerised operation, is a fundamental aspect for the communicative effectiveness of maps. Flood maps can considerably influence the awareness and risk perceptions of the target audience and are therefore crucial in flood cycle management. The introduction of cybermaps and related benefits allows users and decision-makers a greater understanding of floods. The introduction of 3D maps also greatly supports the perception of the hazard, especially for inexpert users.

Critical infrastructures, such as the road transport network, are particularly sensitive to floods and it is difficult to assess in advance the direct and indirect effects that cross the spatial boundaries of the area directly affected by the event. However, given the strategic importance of allowing the movement of goods and people, it is important to understand the interdependencies that may occur. Social media data can support analysis.

This article aims to summarise the main steps for traditional risk mapping and provide guidance for improved coastal flood mapping, identifying the quantity and quality of data source and the use of new technologies as key aspects. However, the lessons of graphic semiology and of overlay techniques remain fundamental. Future developments may lead to more detailed studies on urban coastal flood mapping, both in relation to risks on critical infrastructure and socio-economic systems. In particular, the integration of gradual and event-based hazards into a single map suggests future investigations. 


\section{Acknowledgments}

The data for the elaboration of Figures 7 and 8 were obtained from open source data available online. In particular, the DTM - Digital Terrain Model, has been elaborated starting from the Lidar relief obtained from the Ministero dell'Ambiente e della Tuela del Territorio e del Mare as part of the campaign of the Piano Straordinario di Telerilevamento Ambientale (MATTM) e del Progetto PON - MIADRA, accessible at: http://www.pcn.minambiente.it/viewer/index.php?service $\mathrm{s}=$ LiDAR_Campania. The road infrastructure system was obtained from the database Urban Atlas derived from the Europen Copernicus Land Monitoring Service, accessible at: https://land.copernicus.eu/local/urban-atlas/urbanatlas-2018.

\section{Authors contributions}

The authors jointly conceived and developed the approach, objective and structure of the paper. In particular: Conceptualisation, BB; Methodology, BB, MFC, and ZY; Investigation, $\mathrm{MFC}$ and $\mathrm{ZY}$; Writing-Original Draft Preparation, MFC and ZY; Writing-Review \& Editing, $\mathrm{BB}, \mathrm{MFC}$, and $\mathrm{ZY}$; Visualization, $\mathrm{MFC}$ and $\mathrm{ZY}$; Supervision, BB.

\section{References}

1. 2000/60/EC, Directive of the European Parliament and of the Council of 23 October 2000 establishing a framework for Community action in the field of water policy.

2. 2002/413/CE, Corrigendum to Recommendation 2002/413/EC of the European Parliament and of the Council of 30 May 2002 concerning the implementation of Integrated Coastal Zone Management in Europe.

3. 2007/60/EC, Directive 2007/60/EC of the European Parliament and of the Council of 23 October 2007 on the assessment and management of flood risks.

4. 2013/0074/COD, Proposal for a DIRECTIVE OF THE EUROPEAN PARLIAMENT AND OF THE COUNCIL establishing a framework for maritime spatial planning and integrated coastal management.

5. Addis, D., Maricchiolo, C., Ndong, C., Petit, S., Skaricic, Z. (2015). Pianificazione integrata della fascia marino-costiera. Reticula, progetto reti ecologiche ISPRA, 10: 3-10. Available at: https://www.isprambiente.gov.it/files/pubblicazioni/p eriodicitecnici/reticula/Reticula_n10.pdf.

6. APFM, (2013). Integrated flood management tools series, flood mapping, Associated Programme on Flood Management (APFM), 20. Available at: https://www.floodmanagement.info/publications/tool s/APFM_Tool_20.pdf.

7. Barroca, B., Serre, D. (2018). Risks revealed by cartography - cartography renewed by the geovisualization of risks. International Journal of Cartography, 4(1): 1-3. Available at: doi.org/10.1080/23729333.2018.1444376.
8. Batista, C.M. (2018). Coastal Flood Hazard Mapping. Encyclopedia of Coastal Science. Encyclopedia of Earth Sciences Series, Springer, Cham Available at: doi.org/10.1007/978-3-319-48657-4_356-1.

9. Bertin, J. (1967). Sémiologie graphique : Les diagrammes, les réseaux, les cartes, Paris, GauthierVillars, (first edition).

10. Brivio, P. A., Lechi, G., Zilioli, E. (2006). Principi e metodi di Telerilevamento, CittàStudi Edizioni.

11. Bukvic, A., Rohat, G., Apotsos, A., de Sherbinin, A. (2020). A Systematic Review of Coastal Vulnerability Mapping. Sustainability, 12 (7): 2822. Available at: doi.org/10.3390/su12072822.

12. Coller, M.L.F., Wheeler, P., Kunapo J (2018). Interactive flood hazard visualization in Adobe Flash. Journal of Flood Risk Management, 11(1):134-146. Available at: doi.org/10.1111/jfr3.12188.

13. Cornel, D., Buttinger-Kreuzhuber, A., Waser, J. (2020). Integrated Simulation and Visualization for Flood Management. Special Interest Group on Computer Graphics and Interactive Techniques Conference Talks (SIGGRAPH '20 Talks), ACM, New York, NY, USA 1-2. Available at: doi.org/10.1145/3388767.3408335.

14. Crossland, C., Baird, D., Ducrotoy, J., Lindeboom, H., Buddemeier, R., Dennison, W., Maxwell, B., Smith, S., Swaney, D. (2006). The Coastal Zone - a Domain of Global Interactions. Available at: doi.org/10.1007/3-540-27851-6_1.

15. Excimap, (2007). Handbook on good practices for flood mapping in Europe. EXCIMAP - European exchange circle on flood mapping. Available at: https://ec.europa.eu/environment/water/flood_risk/flo od_atlas/pdf/handbook_goodpractice.pdf.

16. Faghmous, J. H., Kumar, V., (2014). A big data guide to understanding climate change: The case for theoryguided data science. Big Data, 2:155-163. Available at: doi.org/10.1089/big.2014.0026.

17. Gallien, T., Sanders, B., Flick, R. (2014). Urban coastal flood prediction: Integrating wave overtopping, flood defenses and drainage. Coastal Engineering, 91:18-28. Available at: doi.org/10.1016/j.coastaleng.2014.04.007.

18. Hallegatte, S., Green, C., Nicholls, R. et al. (2013). Future flood losses in major coastal cities. Nature Climate Change, 3:802-806 Available at: doi.org/10.1038/nclimate1979

19. Herrington, S. (2010). The Nature of Ian McHarg's Science. Landscape Journal, 29:1-20. Available at: doi.org/10.3368/lj.29.1.1.

20. Houston, D., Cheung, W., Basolo, V., Feldman, D., Matthew, R., Sanders, B., Karlin, B., Schubert, J., Goodrich, K., Contreras, S., Luke, A. (2017). The Influence of Hazard Maps and Trust of Flood Controls on Coastal Flood Spatial Awareness and Risk Perception. Environment and Behavior, 51. Available at: doi.org/001391651774871. 10.1177/0013916517748711.

21. IPCC (2014). Annex II: Glossary. Barros, V. R., Field, C. B., Dokken, D. J., et al. (eds), Climate change 2014: Impacts, adaptation, and vulnerability. Part B: Regional aspects Contribution of Working Group II to 
the Fifth Assessment Report of the Intergovernmental Panel on Climate Change, Cambridge University Press, Cambridge, United Kingdom, 1757-1776. Available at: https:/www.ipcc.ch/report/ar5/wg2/.

22. IPCC, (2018). Global Warming of $1.5^{\circ} \mathrm{C}$. MassonDelmotte, V. et al. (eds), An IPCC Special Report on the impacts of global warming of $1.5^{\circ} \mathrm{C}$ above preindustrial levels and related global greenhouse gas emission pathways, in the context of strengthening the global response to the threat of climate change, sustainable development, and efforts to eradicate poverty. Available at: https://www.ipcc.ch/sr15/.

23. IRGC, (2006). Risk Governance: towards an Integrated Approach. International Risk Governance Council, Geneva, Switzerland. Available at: irgc.org/wp.content/uploads/2012/04/IRGC_WP_No 1_Risk_Governance_reprinted_version_3.pdf.

24. Jacquinod, F., Julien Langumier, J. (2010). Les études d'urbanisme : territoires et usages sociaux des savoirs urbains Stratégies et usages de l'outil à l'occasion de l'étude d'un Plan de Prévention des Risques Inondations. Les études d'urbanisme: territoires et usages sociaux des savoirs urbains, 84 (4) : 303-311. Available at: doi.org/10.4000/geocarrefour.8163.

25. Kellens, W., Terpstra, T., Schelfaut, K., De Maeyer, P. (2013). Perception and communication of flood risks: A literature review. Risk Analysis, 33 (1) : 2449. Available at: doi.org/10.1111/j.15396924.2012.01844.x.

26. Ki, J. (2018). GIS and Big Data Visualization. in Rocha, J., Abrantes, P. (eds), Geographic Information Systems and Science, IntechOpen. Available at: doi.org/10.5772/intechopen.82052.

27. Maceachren, A. M. (1995). How Maps Work: Representation, Visualization, and Design, New York, The Guilford Press.

28. MacEachren, A. M., Kraak, M. J. (2001). Research challenges in geovisualization. Cartography and geographic information science, 28(1): 3-12. Available at: doi.org/10.1559/152304001782173970.

29. McHarg, I. L. (1969). Design with nature, American Museum of Natural History. New York.

30. Nicholls, R.J., Wong, P.P., Burkett, V.R, Codignotto, J.O., Hay, J.E., McLean, R.F., Ragoonaden, S., Woodroffe, C.D. (2007). Coastal systems and lowlying areas Climate Change 2007: Impacts, Adaptation and Vulnerability. Contribution of Working Group II to the Fourth Assessment Report of the Intergovernmental Panel on Climate Change", (eds) M.L. Parry et al., Cambridge University Press, Cambridge, UK, pp. 315-35. Available at: https://www.ipcc.ch/site/assets/uploads/2018/02/ar4wg2-chapter6-1.pdf.

31. Palsky, G. (2012). Map Design vs Sémiologie graphique: Réflexions sur deux courants de la cartographie théorique. Cartes \& géomatique 212 :712. Available http://www.lecfc.fr/new/articles/212-article-1.pdf.

32. Palsky, G., Robic, M.C. (2000). Aux sources de la sémiologie graphique. Cybergeo : European Journal of Geography, Dossiers, document 147. Available at: doi.org/10.4000/cybergeo.554.
33. Pant, R., Thacker, S., Hall, J., Alderson, D., Barr, S. (2018). Critical infrastructure impact assessment due to flood exposure. Journal of Flood Risk Management, 11:22-33. Available at: doi.org/11. $10.1111 / \mathrm{jfr} 3.12288$.

34. Paprotny, D., Morales Napoles, O., Vousdoukas, M., Jonkman, S.N., Nikulin, G. (2019). Accuracy of panEuropean coastal flood mapping. Journal of Flood Risk Management. 12. e12459. Available at: doi.org/10.1111/jfr3.12459.

35. Pregnolato, M., Ford, A., Wilkinson, S. M., Dawson, R. J. (2017). The impact of flooding on road transport: A depth-disruption function. Transportation research part D: transport and environment, 55:67-81 Available at: doi.org/10.1016/j.trd.2017.06.020.

36. Ramieri, E., Bocci, M., Markovic, M. (2019). Linking Integrated Coastal Zone Management to Maritime Spatial Planning: The Mediterranean Experience. Zaucha J., Gee K. (eds) Maritime Spatial Planning, Palgrave Macmillan, Cham, 271-294. Available at: doi.org/10.1007/978-3-319-98696-8_12.

37. Robinson, A., Demšar, U., Moore, $\bar{A}$., Buckley, A., Jiang, B., Field, K., M-J, K., Camboim, S., Sluter, C. (2017). Geospatial big data and cartography: Research challenges and opportunities for making maps that matter. International Journal of Cartography, 3. Available at: doi.org/10.1080/23729333.2016.1278151.

38. Seenath, A., Wilson, M., Miller, K. (2016). Hydrodynamic versus GIS modelling for coastal flood vulnerability assessment: Which is better for guiding coastal management? Ocean \& Coastal Management, 120: 99-109, 2016. Available at: doi.org/10.1016/j.ocecoaman.2015.11.019.

39. Semmo, A., Trapp, M., Jobst, M. Döllner, J. (2015). Cartography-Oriented Design of 3D Geospatial Information Visualization - Overview and Techniques. The Cartographic Journal, 52(2): 95106. Available

at: doi.org/10.1080/00087041.2015.1119462.

40. Serre, D. (2016), "Advanced methodology for risk and vulnerability assessment of interdependency of critical infrastructure in respect to urban floods" in E3S Web Conference, 3rd European Conference on Flood Risk Management, vol. 7, pp. 1-10. [Online] Available at: doi.org/10.1051/e3sconf/20160707002

41. Serre, D., Heinzlef, C. (2018). Assessing and mapping urban resilience to floods with respect to cascading effects through critical infrastructure networks. International Journal of Disaster Risk Reduction, 30: 235-243. Available at: doi.org/ 10.1016/j.ijdrr.2018.02.018.

42. Sluter, Jr. (2001). NEW THEORETICAL RESEARCH TRENDS IN CARTOGRAPHY. Revista Brasileira de Cartografia, 53 (1).

43. Smith R.A.E., Bates P.D., Hayes C. (2012). Evaluation of a coastal flood inundation model using hard and soft data. Environmental Modelling \& Software, 30: 35-46. Available at: doi.org/ 10.1016/j.envsoft.2011.11.008.

44. Smith, L., Liang, Q., James, P., Lin, W. (2017). Assessing the utility of social media as a data source 
for flood risk management using a real-time modelling framework. Journal of Flood Risk Management, 10: 370-380. Available at: doi.org/10.1111/jfr3.12154.

45. Taylor, D. F. (1997). Maps and mapping in the information era. Proceedings of the 18th ICA/ACI International Cartographic Conference, Stockholm, Sweden, 23-27. Available at: https://icaci.org/files/documents/ICC_proceedings/IC C1997/icc1997_volume1_part1.pdf

46. Taylor, D. F. (2003). The concept of cybercartography. Maps and the Internet, Elsevier Science, 405-420. Available at: doi.org/10.1016/B978-008044201-3/50028-1.

47. Van Alphen, J., Martini, F., Loat, R., Slomp, R., Passchier, R. (2009). Flood risk mapping in Europe, experiences and best practices. Journal of Flood Risk Management, 2(4): 285-292. Available at: doi.org/10.1111/j.1753-318X.2009.01045.x.

48. Van de Sande, B., Lansen, J., Hoyng, C. (2012). Sensitivity of coastal flood risk assessments to digital elevation models. Water, 4(3): 568-579. Available at: doi.org/10.3390/w4030568.

49. Vousdoukas, M., Voukouvalas, E., Mentaschi, L., Dottori, F., Giardino, A., Bouziotas, D., Bianchi, A., Salamon, P., Feyen, L. (2016). Developments in large-scale coastal flood hazard mapping. Natural Hazards and Earth System Sciences. 16:1841-1853. Available at: doi.org/10.5194/nhess-16-1841-2016.

50. Vousdoukas, M.I., Ferreira, Ó., Almeida, L.P. et al. (2012). Toward reliable storm-hazard forecasts: XBeach calibration and its potential application in an operational early-warning system. Ocean Dynamics, 62: 1001-1015. Available at: doi.org/10.1007/s10236-012-0544-6.

51. Wang, C., Hou, J., Miller, D., Brown, I., \& Jiang, Y. (2019). Flood risk management in sponge cities: The role of integrated simulation and $3 \mathrm{D}$ visualization. International Journal of Disaster Risk Reduction, 39, 101139. Available at: doi.org/10.1016/j.ijdrr.2019.101139.

52. Yamazaki, D., Ikeshima, D., Tawatari, R., Yamaguchi, T., O'Loughlin, F., Neal, J., Sampson, C., Kanae, S., Bates, P. (2017). A high-accuracy map of global terrain elevations: Accurate Global Terrain Elevation map. Geophysical Research Letters, 44. Available at: doi.org/10.1002/2017GL072874.

53. Zhu, X., Linham, M.M.e Nicholls, R.J (2010). Technologies for Climate Change Adaptation Coastal Erosion and Flooding. Technical Report, 166 Available at: https://www.climatesmartplanning.org/sites/cspp/file s/TNA_Guidebook_AdaptationCoastalErosionFloodi ng.pdf. 